\title{
A SECOND CASE IN THE SAME FAMILY OF CONGENITAL FAMILIAL CEREBRAL LIPOIDOSIS RESEMBLING AMAUROTIC FAMILY IDIOCY
}

\author{
BY
}

\author{
N. J. BROWN, BERYL D. CORNER and M. C. H. DODGSON \\ From the Departments of Pathology and Child Health, Southmead Hospital, Bristol, and the Burden Mental Research \\ Department, Stoke Park Colony, Stapleton, Bristol
}

(RECEIVED FOR PUBLICATION OCTOBER 26, 1953)

We owe to Norman and Wood (1941) the observation that a disorder resembling amaurotic familial idiocy may originate during the prenatal period and be fully established at birth. Although the importance of this condition was appreciated by Globus (1942), no comparable cases have been reported subsequently. On the other hand, the question of cerebral lipoidosis in early infancy has been fully investigated by Giampalmo (1949) and by Videbaek (1949). In none of the cases reviewed by those two authors, either of the neurological form of Gaucher's disease (30) or of Niemann-Pick disease (73), was the condition undoubtedly present at birth.

A younger sibling of Norman and Wood's original case has recently died in infancy, the main features in the two being almost identical. The condition which these two cases exemplify is thus a familial one whose occurrence appears to be unique in the literature.

\section{Case Report}

Margaret C. was born at Southmead Hospital, Bristol, on March 26, 1951. The pregnancy, which had been normal, was of approximately 36 weeks' duration and terminated after a 15-hour labour with a normal vertex delivery. The placenta appeared normal and weighed $1 \mathrm{lb} .6 \mathrm{oz}$. The infant was only slightly asphyxiated at birth, breathed almost immediately and required no resuscitative measures other than aspiration of some meconium-stained fluid from the pharynx, and no abnormality in her appearance was noted then. The weight at birth was $4 \mathrm{lb}$. $1 \mathrm{oz}$., body length $16 \frac{1}{2}$ in., head circumference $11 \frac{1}{2}$ in., shoulder diameter $4 \frac{1}{2}$ in., intertrochanteric diameter $4 \frac{1}{2}$ in. During the first four hours of life her condition gave rise to anxiety. Moderate generalized oedema developed, with increased tone in the limbs, amounting to rigidity. There was generalized twitching whenever she was disturbed, and a shrill cry. The anterior fontanelle was small with no increased tension and there was no neck rigidity. In an oxygen tent her colour was normal, although slight cyanosis developed after episodes of twitching.
Her respiration was noted to be abnormal, shallow and very irregular, varying in rate from 44 to 54 respirations a minute, with occasional deep, gasping breaths. The air entry into the lungs was quite good and no adventitious sounds were heard. After $\mathbf{4 8}$ hours there was no evidence of oedema, but her condition otherwise was unchanged and as she appeared unable to suck or swallow, feeding by gavage was begun.

During the next 10 days her condition deteriorated. She regurgitated frequently and occasionally vomited larger quantities. Body temperature showed marked thermolability (Fig. 1), which remained an outstanding feature of the case. On the eighth day she suddenly became very much worse with completely irregular respiration, characterized by periods of apnoea of one to two minutes' duration followed by loud, crowing gasps suggestive of laryngeal spasm. The chest showed recession of the lower ribs, diminished basal air entry and some coarse râles. Rigidity was more marked, head retraction developed, and twitching became so severe that feeding was difficult. Lumbar puncture was attempted but no fluid could be obtained. Chloral was administered frequently and also procaine penicillin, as pulmonary infection was feared. Fluid intake was maintained by a subcutaneous drip.

On April 10, when she was 15 days old, her condition was unchanged but it was observed that the general shape of the head was scaphocephalic, with a very poorly developed frontal region and the bi-temporal diameter appeared unusually narrow. Sutures were palpated with difficulty and the anterior fontanelle was almost closed. Throughout the third week her condition remained very poor; she was constantly rigid, in marked opisthotonos, with the limbs held in extension. Her colour became pale and occasionally greyish, but there was never any clinical jaundice. Troublesome abdominal distension was relieved by a flatus tube, regurgitation ceased and oesophageal feeds were well retained, although twitching often made passage of the tube difficult. On the seventeenth day hyperpyrexia with a temperature of $108^{\circ} \mathrm{F}$. developed but no signs of infection could be found. Lumbar puncture was again performed and clear, colourless fluid withdrawn under normal pressure.

At the end of four weeks she was clearly still a very 
abnormal baby. Her weight was $4 \mathrm{lb} .12 \mathrm{oz}$. The head circumference was 12 in. and the shape unchanged. She lay in opisthotonos, pale and convulsing whenever disturbed. Respirations were still irregular and the crowing cry persisted. At this time it was noticed that she had no blink reflex and made no attempt to look at the nursing staff or at dangling objects. Gavage feeding

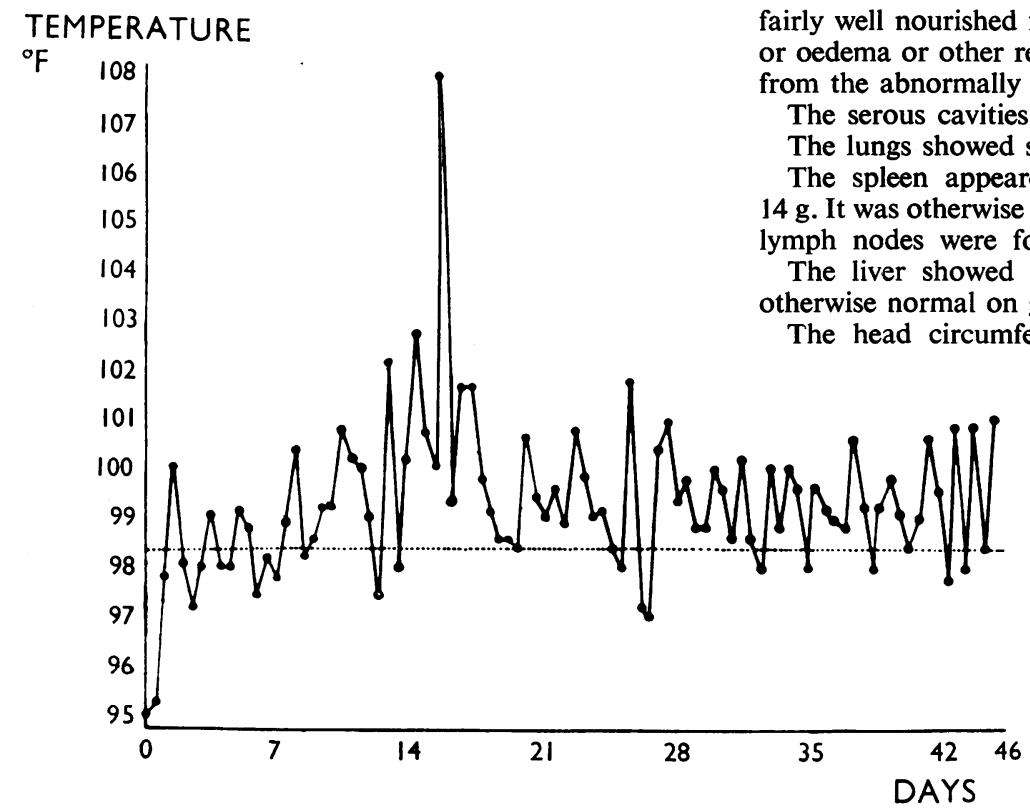

who is a certified mental defective, and an aunt who has been in an institution for 'mental trouble'. The mother, aged 37 , has no family history of mental or nervous disorder. The patient was the eighth child in the family, and there has been another sibling since, who is apparently normal and healthy (Table 1).

Necropsy Findings.-Post-mortem examination .was carried out 18 hours arter death. The body was that of a fairly well nourished female infant showing no jaundice or oedema or other remarkable feature externally, apart from the abnormally shaped head described below.

The serous cavities were normal.

The lungs showed some basal congestion only.

eared slightly enlarged and weighed ise normal in appearance. No enlarged re found. therwise normal on gross examination.

ce was 12 in. The skull was abnormal in shape, the anteroposterior diameter being long and the bi-temporal diameter abnormally short. The vault of the skull was tall and scaphocephalic. The sutures were not united and the anterior fontanelle was not quite closed.

On opening the skull there was found to be a very considerable degree of external hydrocephalus. The brain was very small and firm with a very much simplified convolutional pattern and lay deep down in the base of the skull like a shrunken walnut within its shell, the greater part of the cranial cavity being occupied by cerebrospinal fluid. A skiagram of the head after removal of the fluid (Fig. 2) shows clearly the relative proportions of the brain and the cranial cavity.

TABLE THE SIBLINGS OF M.C. all retinal vessels. The pupils were equal and there only slight reaction to light.

By May 12 her condition was very much worse, with continuous hiccough and convulsions, despite heavy sedation. She died on May 14 at the age of 7 weeks. Just before death her weight was $5 \mathrm{lb} .8 \mathrm{oz}$.

Investigations.-In a specimen of cerebrospinal fluid, taken on April 12, there were 6 leucocytes per c.mm., and 145 erythrocytes per c.mm.; the value for protein was $70 \mathrm{mg} . \%$ and there was a slight excess of globulin; there was $78 \mathrm{mg}$. \% of sugar; the sample was sterile on culture. The urine on April 9 contained a trace of protein and numerous epithelial cells, yielding a scanty growth of Bact. coli. On April 9 the haemoglobin level was $128 \%$, falling to $70 \%$ on May 7 ; the blood urea on the former date was $46 \mathrm{mg}$. \%. A sample of maternal blood was Group $\mathrm{O} R \mathrm{R}$ positive and gave a negative Kahn reaction.

Family History.-The parents are both healthy, of English nationality and with no history of Jewish extraction. There is no consanguinity. The father, aged 36 , is employed as a saw-mill labourer, has one brother 
The brain, fixed in $10 \%$ formol-saline, weighed $65 \mathrm{~g}$. (At birth the brain normally weighs approximately 300 g.)

The leptomeninges loosely covered the surface of the firm, shrunken cerebrum, the cerebral vessels being normal in appearance and distribution. The straight, unbranched central sulci were conspicuous, as were

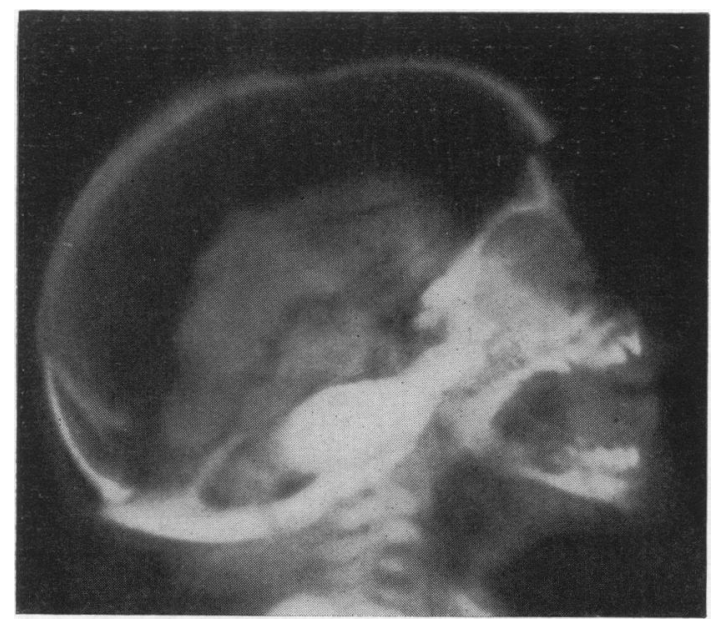

Fug. 2.-Skiagram of skull taken at necropsy, with the brain still in situ. The calvarium had been sawn through and replaced.

broad deep calcarine and lateral fissures, the latter leaving the insulae widely exposed. A simple sulcal pattern in the frontal lobes contrasted with more complex fissuring in the parieto-occipital region (Fig. 3).

The cut surface of the cerebrum was rigid and greyish white, appearances being those of an extreme sclerosis. Demarcating the narrow pale cortex (1-1.5 mm. thick), there was a fine, ivory-white line at the cortico-medullary junction, which proved to be particularly rich in lipoids. There was a fine, spongy reticulation of the subcortical white matter, particularly at the summits of gyri. Deeper in the centrum ovale there were occasional creamy-white deposits of lipoid, 1-3 mm. in diameter. The tissue as a whole had evidently shrunk considerably, as was shown not only by its abnormal firmness but also by an almost total absence of further shrinkage during the embedding of blocks from the cerebrum in paraffin wax.

The brain-stem, cerebellum, medulla oblongata and spinal cord were small in proportion to the cerebrum, their cut surfaces being firm and pale. Seen from the side, the cerebellar hemispheres were somewhat flattened. There was an area of total cortical atrophy of approximately $5 \mathrm{~mm}$. diameter on the inferior surface of the left hemisphere loosely covered by leptomeninges (Fig. 3). The other organs of the body showed no abnormalities on naked-eye examination.

Histological Findings.-The following are descriptions of the histology, particularly of the brain and central nervous system.
SPLEEN. The pulp contained numerous large rounded cells with clear outlines, small indistinct nuclei and abundant cytoplasm which contained numerous tiny droplets of weakly sudanophil material giving the whole cell a ground-glass appearance. These cells were found singly and in small groups.

LUNG. There was patchy collapse and bronchopneumonia. Some histiocytic cells containing lipoid were present.

THYMUs. The cortex was normal. The medulla showed a normal number of Hassall's corpuscles. It also contained some rounded opaque cells containing sudanophil lipoid.

KIDNEY. Some lipoid-containing cells were present.

ADRENAL. A number of similar cells were found in the medulla.

Central Nervous System.-The central nervous system was examined using frozen sections from blocks taken from the cerebral hemisphere, mid-brain, pons, cerebellum, medulla and spinal cord. The right cerebral hemisphere was used for chemical analysis. Sections from each block were stained with Azur A ( $p \mathrm{H} \mathrm{4})$ by the Kultschitsky-Pal myelin method, Holzer's glial fibre method, Bielschowsky's neurofibril method and with Sudan III. Various sections were also used for Penfield's combined oligo- and micro-glial method, and for the globus method for astrocytes.

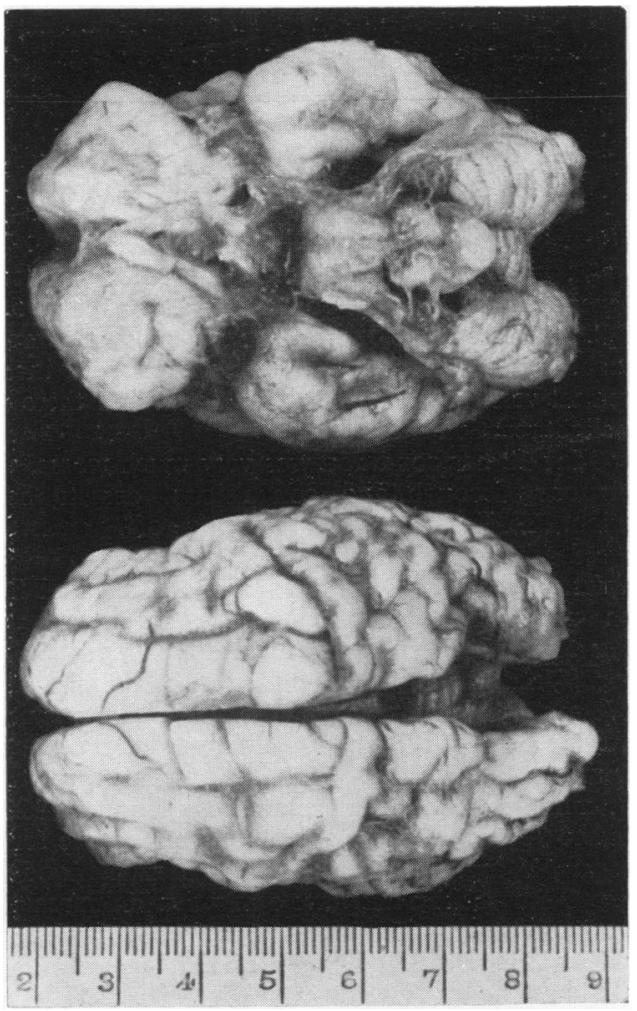

FiG. 3.-Basal and superior aspects of the brain. 
Most of the nerve cells in the cerebral cortex showed morphological changes resembling those seen, in this situation, in the earlier forms of infantile amaurotic family idiocy. The cells in question had become 'fossilized'; they were spherical, hyaline or indistinctly granular masses, each containing one or more nuclear remnants, devoid of Nissl substance and no longer recognizable as neurons (Fig. 4). Similarly, enormous numbers of cells throughout the cerebral white matter, no longer recognizable either as normal astrocytes or microglial cells, were distended with lipoid substances. As a consequence of the shrunken state of the tissue, extreme crowding of cortical cells was evident in frozen sections and was scarcely more marked in paraffin-embedded

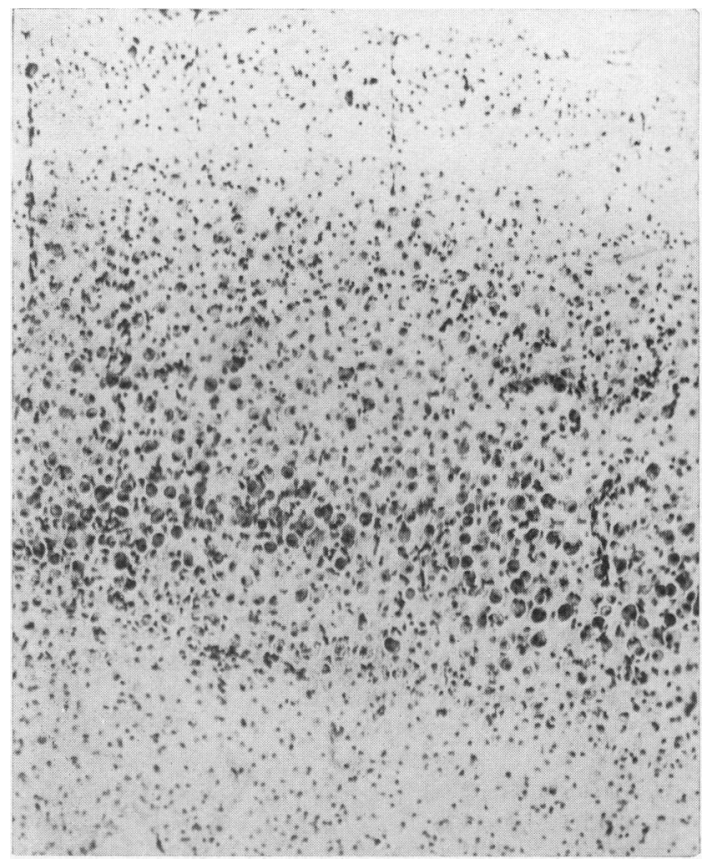

Fig. 4.-Frozen section of the cerebral cortex in the occipital region. Azur A $\times 80$.

ones. Although glial fibrils could not be demonstrated in the cerebral cortex nor in much of the subcortical white matter, staining with aniline blue showed the ground substance of both to consist of a relatively coarse meshwork, to whose presence the unusual rigidity of the tissues may perhaps have been related. It was not possible to demonstrate the presence of morphologically normal astrocytes, nor were attempts to impregnate the microglia successful. Nevertheless, in Nissl preparations, nuclei characteristic of microglial cells were present in apparent excess in the cerebral cortex, white matter and elsewhere, notably in subcortical centres where the more severe type of nerve cell change had occurred, or where there was evidence of nerve cell loss, e.g., in the inferior olivary nuclei. Occasional small rounded nuclei, thought

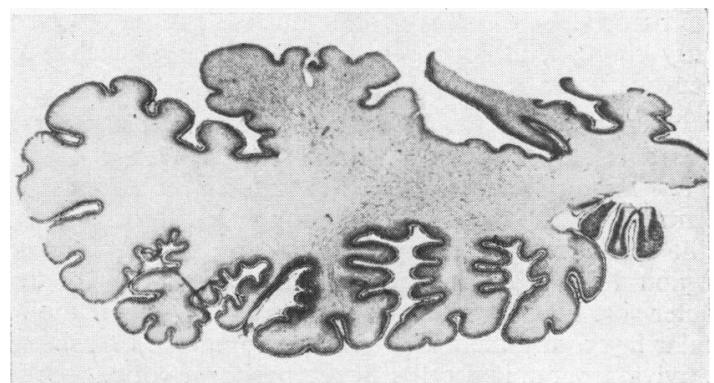

FIG. 5.-Frozen section through the long axis of the left cerebellar hemisphere. Azur A $\times 1.4$

to be of oligodendroglial cells, were seen in those regions of the medulla oblongata and spinal cord where normal myelination had occurred, but not in other situations. The basal ganglia, internal capsule, and thalamus were together the site of a dense glial fibrosis which extended downwards into the substantia nigra and tectal region of the midbrain. A less dense, fairly evenly distributed fibrosis was found involving the pons, medulla oblongata and spinal cord.

The Cerebellum. There was marked atrophy of the cerebellum, affecting the hemispheres (Fig. 5) more than the vermis (Fig. 6) and, in the latter situation, almost entirely sparing the median and flocculonodular lobes. Minimal glial fibrosis accompanied the atrophic changes in the anterior lobe, although the former process was more marked, laterally, in the hemispheres. The more nearly normal parts of the cortex contained unaltered Purkinje cells; most however, showed varying degrees of fatty change, a small proportion having become the rounded hyaline bodies characteristically present in the cerebral cortex. Many Purkinje cells thus severely affected lay in the internal granular layer and in a small heterotopic area of grey matter in the flocculonodular lobe. In the anterior lobe, sparseness of cells in all three layers of the cortex, with absence of Purkinje cells at the tips of the atrophied folia, contrasted with more nearly normal appearances of the cortex bordering the depths of

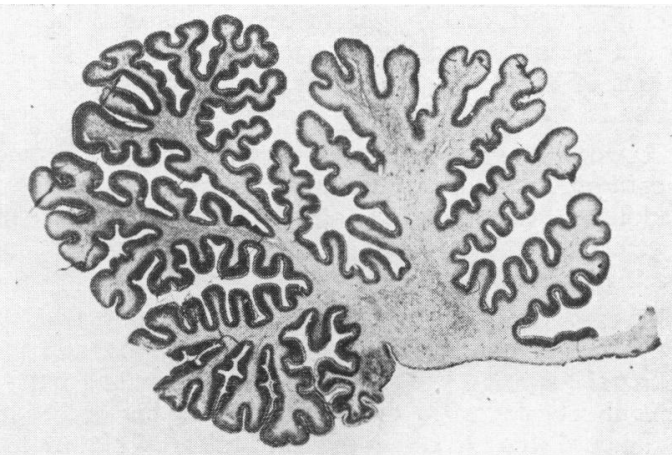

FIG. 6.-Frozen section, in the sagittal plane, through the vermis of the cerebellum. Azur $A \times 5$ 
the fissures. Cells in the dentate nucleus showed marked fatty changes, although they were still recognizable as neurons.

Cerebral Cortex. Within the cerebral cortex there was a relative sparing of nerve cells in certain areas: a few large pyramidal cells in the fifth layer of the precentral cortex (area FA) although much shrunken, still retained their neuronal structure; in the insular region there were numerous Cajal cells lying on the outer side of a dense plexus of fibres in the outer molecular layer, and the fifth layer also contained occasional surviving pyramidal cells; in the pyriform cortex, particularly in its forward extension onto the gyrus semilunaris, many neurons were relatively little damaged. On the other hand, definite evidence that nerve cells had disappeared during the course of the disease was not obtained except in the pyramidal cell layer of the cornu ammonis, where a dense glial fibrosis marked the site of an outfall of cells.

OTher Centres. There was neuronal damage, comparable to that seen in the cerebral cortex, with varying degrees of nerve cell loss and gliosis, in the corpus striatum, subthalamic region, red nucleus, pontine and olivary nuclei. In the last-named group, the dorsal accessory nucleus (related to the vermis of the cerebellum) showed better preserved nerve cells and less marked gliosis than was seen in the main olivary nucleus. The medial and lateral geniculate bodies showed severe changes, as did the greater part of the thalamus. The lateral nuclear mass of the thalamus, however, contained numerous large cells which, although distended with lipoid, were recognizable as neurons and lay in an apparently normal neuropil. A radiation of fine unmyelinated fibres passed from the anterior part of this region into the cortical white matter of the more posterior part of the frontal lobe, although very few of these fibres reached the cortex. Nerve cell morphology was fairly well preserved in the hypothalamic region.

Nissl substance and intracytoplasmic neurofibrils, associated with an apparently normal neuropil, were demonstrable in motor cells from the occulomotor nuclei to the anterior horns of the spinal cord. The motor cells, however, as well as nerve cells related to afferent systems, for example, in the posterior horns, the posterior column nuclei and nuclei of sensory cranial nerves, almost without exception contained large single accumulations of lipoid. Nerve cells in Gasserian ganglion also showed these changes.

Cranial Nerves. The optic nerves were thin, heavily gliosed and contained no more than occasional nonmedullated axones. The olfactory nerves were unmyelinated. The remaining cranial nerves showed no specific abnormalities.

Myelination. On comparing the following findings with those of Langworthy (1933) in human prenatal and neonatal material, it was evident that there had been a general retardation in the maturation of the brain and spinal cord. Interpretation of the histological picture was complicated by the poverty of myelinated fibres in parts of the cerebrum and cerebellum where myelin is normally deposited before birth, but which, in this instance, showed particularly severe pathological changes.

No more than occasional thickened and distorted myelinated fibres were detectable microscopically in the corona radiata, internal capsule, crus cerebri and in the ventrolateral region of the thalamus. Similarly, sparse myelination was seen in the fibre capsule of the subthalamic nucleus and in the red nucleus. On the other hand the heavily gliosed globus pallidus, normally well myelinated in the 8-month-old human foetus, contained no neuropil and was practically unmyelinated. At a single level in the midbrain, extremely scanty microscopically visible myelination could be identified in the occulomotor nerve, commissure of the inferior colliculus, tectospinal fibres, brachium conjunctivum, lateral spinothalamic fibres and medial lemniscus. Myelination of pathways in the pons was heavier than in the midbrain, and in the medulla and spinal cord, more complete than in the pons. The intracranial portions of the cranial nerves, from the third nerve onwards, were well myelinated, as was the fibre capsule of the inferior olivary nucleus and the reticular substance in the medulla. There were a few very thinly myelinated fibres in the pyramidal tracts, although non-myelinated fibres appeared to be more numerous. A number of well myelinated spino-cerebellar fibres entered the superior and inferior peduncles, which were otherwise non-myelinated, as was the middle peduncle. In the vermis of the cerebellum the whole of the white matter was thinly myelinated, although in the hemispheres very scanty myelination was confined to those folia, mainly on the inferior surface, exhibiting a relatively less severe degree of atrophy. Myelination in the cervical region of the cord with the exception of a marked retardation in the posterior columns, was at about the stage of completion normally reached at birth (Fig. 7).

Histochemical Findings. - It was possible to perform a limited number of histochemical tests on frozen sections of the formalin-fixed brain tissue.

Large, single, intracytoplasmic globules of strongly sudanophilic substances were found in glial cells, evenly distributed throughout the cerebral white matter, with occasional small dense focal aggregates. This substance was readily soluble in alcohol and was thought to consist

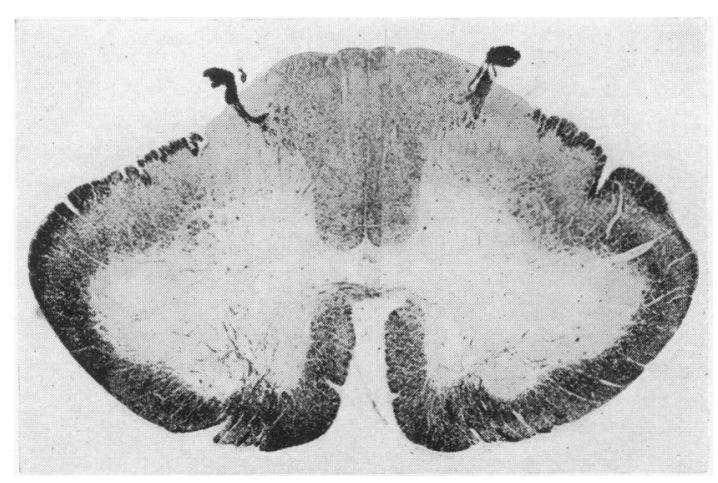

FIG. 7.-Transverse frozen section through the cervical enlargement of the spinal cord. Kultschitsky-Pal method for myelin sheaths $\times 2 \cdot 8$. 
of neutral fat. There were also small needle-like crystals, some lying extracellularly, others within globules of neutral fat; they stained lightly with osmic acid, gave a play of colours with equal parts of acetic and sulphuric acids and were readily soluble in alcohol and other solvents. No change followed treatment with digitonin, although occasional Maltese cross forms were seen with polaroid lenses on heating sections to $56^{\circ} \mathrm{C}$. and recooling. The crystalline material was thought to consist of cholesterol and/or its esters. Lipoid in the white matter stained with haematoxylin in the Kultschitsky-Pal myelin method after mordanting for periods of up to 48 hours; after more prolonged mordanting it became progressively less deeply stained, in this respect resembling normal myelin.

Unlike the glial cells in the white matter and in the cortex nerve cells in the latter situation were only faintly sudanophilic and still retained a faint propensity for staining with Scharlach $\mathbf{R}$ after immersing the sections in acetone, ether, pyridine, ethyl alcohol and boiling chloroform. The residual material was basophilic, gave a positive periodic acid-Schiff reaction, had a marked affinity for aniline blue and cresyl violet and showed faint acid-fast staining with carbol-fuchsin. With prolonged mordanting, the lipoid in cortical nerve cells stained progressively more darkly after 48 hours, reaching maximal intensity after four to five days. In this respect the staining of intraneuronal lipoid differed from that of fatty material in the white matter, although resembling the behaviour of erythrocytes within cortical blood vessels

Chemical Analysis of Formalin-Fixed Cerebrum.Quantitative chemical estimations were made of one cerebral hemisphere from case M.C. (Table 2) and of a

TABLE 2

CHEMICAL ESTIMATIONS

\begin{tabular}{l|c|c|c|c}
\hline & $\begin{array}{c}\% \text { Cholesterol } \\
\text { in Dry Extract }\end{array}$ & $\%$ Phosphatide & $\begin{array}{c}\% \text { P in } \\
\text { Lipoid } \\
\text { Extract }\end{array}$ & $\% \mathrm{H}_{2} \mathrm{O}$ \\
\hline $\begin{array}{c}\text { M.C. .. } \\
\text { Control } \\
\text { Conatal }\end{array}$ & $15 \cdot 3$ & $7 \cdot 6$ & 0.333 & 82.8 \\
\hline
\end{tabular}

control neonatal case by $\mathrm{Mr}$. A. H. Tingey. In both instances the brain had been in $10 \%$ formalin for approximately one year. Certain results showed significant departures from normal values. The presence of an excess of cholesterol is in accordance with the histological findings. Estimation of phosphatide in formalin-fixed brains is liable to give erroneous results due to the occurrence of hydrolysis. Thus the low value obtained for M.C. might not be due entirely to the poverty of myelin in the cerebrum. Values obtained for phosphorus in the lipoid extracts were thought to give some indication of the nucleoprotein content of this tissue. The significance of the low value obtained for M.C. is not clear.

\section{Discussion}

The clinical features of this case are of some interest. The abnormal appearance of the skull, which was recognized almost from birth, suggested that some degree of craniostenosis was present which might be associated with microcephaly or other maldevelopment. This possibility was greatly increased by the discovery of abnormal fundi oculi in the fifth week of life. An altered respiratory pattern was perhaps the most striking and constant clinical feature, the irregular gasps and periods of apnoea indicating that there was little control of the medullary and pontine functions by higher centres of the brain. These observations, in conjunction with the picture of decerebrate rigidity which developed, made the diagnosis of a gross brain lesion certain. In the elder sibling (Norman and Wood's case), feeding difficulty was the chief symptom. It is therefore worthy of note that in the present case sucking and swallowing reflexes were completely absent throughout the seven weeks of the child's life, and only very skilled nursing kept her alive so long and even enabled normal general bodily growth.

The occurrence of this disorder twice in a large family of otherwise healthy siblings suggests that, as in Tay-Sachs and Gaucher's disease, it is determined by the presence of a recessive gene. The two main theories advanced to explain the production of Tay-Sachs disease are: (1) that it is primarily a disorder of lipoid metabolism; (2) that the 'hyaloplasm' of nerve and glial cells has an inherent tendency to become loaded with fatty substances (Schaffer, 1930). In support of the first hypothesis must be mentioned the occurrence of small lipoidal deposits in macrophages outside the central nervous system, as was described by Bielschowsky (1928) and as has been seen in the two congenital cases. Similarly, Klenk's identification (Klenk, 1939, 1941) in the tissue of a lipoidal substance, supposedly not present in any appreciable amount in healthy central nervous tissue, has also been advanced in support of the former theory. It is unfortunate that in neither congenital case has it been possible to study Klenk's compound in the formalin-fixed tissue. In the present case the finding of an excess of cholesterol is of interest, although this substance is deposited in many degenerative conditions of the brain.

An increased consistency of the brain in Tay-Sachs disease has often been noted. The brain at necropsy may be rubbery, as in a case described by Baker and Platou (1938). In both congenital cases there was a marked change in the physical state of the brain. Histological differentiation of nerve centres and myelination of fibre tracts had, nevertheless, already 
begun. It appeared, therefore, that some catastrophic event, perhaps involving dehydration of the ground substance, with consequent shrinkage of the tissue, had occurred during the last months of pregnancy.

The pathological findings were of particular interest in relation to the selective vulnerability of certain centres. As not infrequently occurs in infantile amaurotic familial idiocy, there was marked atrophy of the cerebellum in both congenital cases. In the present case the size and degree of differentiation of the cerebellar vermis corresponded closely with that of a normal $230 \mathrm{~mm}$. embryo, that is one of 28 to 32 weeks' gestation (Hochstetter, 1929). A comparable vulnerability of the cerebellum at a late stage in its development has been demonstrated by Hicks, Schaufus, Williams and Cooney (1952), who obtained cerebellar defects in mice which had been submitted to ionic radiation during the last few days of intra-uterine life.

In the cerebral cortex, studies by Vogt (1929) and earlier authors showed that although the nerve cell changes in amaurotic family idiocy are generalized, there are variations in the presumed rapidity with which cells succumb, in the intensity of the neuroglial reaction and in the degree of vascularity in different cortical areas. Nerve cell changes in the cerebral cortex in each of the two congenital cases were more severe than are usually seen in the infantile form of the disease. The survival of occasional structurally recognizable large pyramidal cells in the fifth layer of the precentral region is of some interest, since the latter are among the earliest cortical neurons to undergo histological differentiation. Findings in the cerebral cortex were therefore also in accordance with the view that the foetal brain had sustained damage at a late stage in its development.

\section{Summary}

A second case of congenital cerebral lipoidosis is described in a younger sibling of a case reported by Norman and Wood (1940). The present infant, also a girl, was recognizably microcephalic at birth and survived for six weeks. The histopathological changes in the central nervous system, almost identical in the two cases, have a general resemblance to those of infantile amaurotic family idiocy. An excess of cholesterol was found in the white matter. Following prolonged extraction with solvents, an insoluble Schiff-positive lipoidal residue remained within the cytoplasm of nerve cells of the cerebral cortex and elsewhere.

We are grateful to Dr. R. M. Norman for his helpful interest in the neuropathological findings, also to $\mathrm{Mr}$. C. A. Brown, F.R.C.S., for his ophthalmological report. Our thanks are due to Mr. A. H. Tingey for performing the chemical analyses, to Mr. R. J. Hart for the histological preparations and to Mr. A. Churchill for the photographs.

\section{REFERENCES}

Baker, A. B. and Platou, E. S. (1938). Arch. Path., Chicago, 25, 75.

Bielschowsky, M. (1928). J. Psychol. Neurol. Lpz., 36, 103

Giampalmo, A. (1949). Acta paediat., Uppsala, 37, 6.

Globus, J. H. (1942). J. Mt Sinai Hosp., 9, 451 .

Hicks, S. P., Schaufus, C. A., Williams, A. A. and Cooney, R. C. (1952). J. Pediat. 40, 489.

Hochstetter, F. (1929). Beiträge zur Entwicklungsgeschichte des menschlichen Gehirns. Vienna.

Klenk, E. (1939). Hoppe-Seyl, Z. physiol. Chem., 262, 128.

(1941). Ibid., 268, 50.

Langworthy, O. R. (1933). Contr. Embryol. Carneg. Instn., No. 139, 24, 1 .

Norman, R. M. and Wood, N. (1941). J. Neurol. Psychiat., 4, 175.

Schaffer, K. (1930). Arch. Psychiat. Nervenkr., 89, 814.

Videbaek, A. (1949). Acta paediatr., Uppsala, 37, 95.

Vogt, M. (1929). Encéphale, 24, 509. 